\title{
Analysis of Memory, Gender, and Identity in Psychological Thrillers with Specific Reference to Alfred Hitchcock's Spellbound and James Mangold's Identity
}

\author{
Merin Susan John ${ }^{1}$ \\ ${ }^{1}$ Jyoti Nivas College, Bangalore, India
}

\begin{tabular}{|c|c|}
\hline Article Info & Abstract \\
\hline $\begin{array}{l}\text { Article history: } \\
\text { Received. } 08 \text { August } 2020\end{array}$ & $\begin{array}{l}\text { Purpose: This paper aims to analyze the portrayal and presentation of } \\
\text { memorv, gender, and identity in selected psvchological thrillers. }\end{array}$ \\
\hline $1^{\text {st }}$ Revision: 18 September 2020 & Approach/Methodology/Design: The selected films are Alfred Hitchcock's \\
\hline $2^{\text {nd }}$ Revision:08 October,2020 & Spellbound and James Mangold's Identity. For the analysis of these films, \\
\hline ctober 2020 & $\begin{array}{l}\text { the researcher employs both narrative and structural approaches; thematic } \\
\text { analysis, psychoanalysis, and also feminist film theorv. }\end{array}$ \\
\hline Keywords: & Findings: The results of the analysis show that apart from building suspense \\
\hline & and mysteries with the identity issue, these thrillers question the stereotypes \\
\hline Identity, & and inequality in society through the female characters for the consumerist \\
\hline $\begin{array}{l}\text { Film Studies, } \\
\text { Visual Image. }\end{array}$ & audience. Hence, these films attempt to break the chains of legitimated \\
\hline Gender & $\begin{array}{l}\text { stereotypes in the soclety which create binarles in the lives of people. } \\
\text { Practical Implications: The portrayal of illness in psychological thrillers }\end{array}$ \\
\hline Paper Type: & $\begin{array}{l}\text { has attracted a lot more audience to seats. Dissociative elements such as } \\
\text { memory and identity of the mind perhaps have permeated the film-going }\end{array}$ \\
\hline Research Article & experience. The paper showcases these aspects in the selected films. \\
\hline $\begin{array}{l}\text { Corresponding Author: } \\
\text { Merin Susan John } \\
\text { Email: } \\
\text { merinsusan321@gmail.com }\end{array}$ & $\begin{array}{l}\text { Originality/value: The picturization of the fading identity and the double } \\
\text { personality of the characters are central to the interior experience. The } \\
\text { capturing of Amnesia and its related themes of memory, identity, and } \\
\text { distributed consciousness are common materials in recent films because } \\
\text { they can stretch to basic humanistic concerns and contemporary psycho- } \\
\text { social issues. }\end{array}$ \\
\hline
\end{tabular}

\section{Introduction}

A film is a form of visual art that is used to communicate ideas, stories, perceptions, feelings, beauty, or atmosphere. This form of a text can be considered also as a cultural artefact created by cultures around the universe. It is recognized to be an essential art form and a source of entertainment. Films are a source of an effectual visual medium for educating citizens and the visual specialties of films give it a universal command of expression.

The study of film has survived for quite some period presently as an autonomous discipline, notably in the Anglo-American world. Since its discovery a hundred years ago, films have also contributed to the emergence of a diverse cinematic genres and forms. Because of its visual command, the visual factor plays only a subsidiary role in fiction. The film is hastily classified as a dramatic genre. Typical elements of the paperback varied narrative techniques, innovative structuring of the plot, foreshadowing and flashback, the difference of setting and time composition are generally employed in films. 
Cinematic adaptations of narrative literature were born out at the turn of the century in America. Amongst the earliest narrative films are children's tales such as Georges Méliès Cinderella (1899) or novels such as Gulliver's Travels (1726) and short stories such as The Legend of Rip Van Winkle (1820). While the early films simply selected the severe perspective of the proscenium frame, the genre withdrew from drama shortly before and during World War I. New methods such as camera movement and editing were invented. An early American model in which these new techniques are implemented is D.W.Griffith's epic narrative film about the United States' rise to power, The Birth of a Nation (1915). Several other major genres, such as the Western, slapstick comedies and love stories were then existent in the initial American silent movie. Already by World War I, Hollywood had climbed to be the centre of the film industry, with a broad network of cinemas all across America.

Outside America, the Russian filmmaker Sergei Eisenstein was one of the essential personalities in film chronicle, inventing unlike techniques in the area of film editing in the years later the Russian Revolution. In Germany amid the wars, Robert Wiene's Das Cabinett des Dr. Caligari (1919) and Fritz Lang's Metropolis (1926) were notable additions to Expressionist Film. Inspired by psychoanalysis, Expressionist Film added a unique dimension to the medium, for example, to visualize dreams and other psychological aspects. When the sound was presented to film in the mid-1920s, some of the regular visual techniques of the silent era were abandoned for a brief while in favor of sound and music. Because of the sheer influence of sound equipment, camera mobility was initially hindered. The acoustic dimension allowed the construction of action into dialogues and not utterly through the visual means of the earlier decades. By the 1930s, Hollywood's genres incorporated the Western, the musical, gangster and adventure movies, science fiction, the horror film, and opulent costume epics. After World War II, film noir (dark film) emerged as a new genre dealing with exploitation in the disillusioned society of the American center. Billy Wilder's Double Indemnity (1944) and Robert Siodmak's The Killers (1946) are some popular examples.

In post-war Europe, the Italian Neo-Realist Film grew internationally celebrated through directors like Roberto Rosselini, who used realistic issues in real surroundings. In these films, the directors attempted to capture the common life of post-war Italy by snapping away from the artificiality of the 'closed' studio circle and thereby founding novel cinematic forms. In the late 1960s, French directors such as Jean-Luc Godard and François Truffaut earned international recognition for their innovations in films (Glenn, 2014). Through the Neuer Deutscher Film (New German Cinema), including the directors Rainer Werner Fassbinder, Werner Herzog, and Wim Wenders, the German film experienced the new international fame, which it had failed for some time. In the 1980s, young African American filmmakers were able to build themselves adjacent to Hollywood directors. Spike Lee's Do the Right Thing (1989) and John Singleton's Boyz $N^{\prime}$ the Hood (1991) are examples of a movement which in literary criticism had grown to be known as 'Minority' studies of literature, including African American, Chicano, Gay, and Lesbian self-expression. In films, 
as in other genres, multiple levels offer to the overall artistic print. This medium, which greatly relies on technical features, has diverse importance, unique cinematic features with their language. The most vital factors of a film can be subsumed following the dimensions of space, time, and sound.

The history of films within the nineteenth century is nearly compared thereupon of photogrammetry. A quick series of individual shots create for the human eye the pattern of a moving picture. To build this illusion, twenty-four pictures per second have to be combined. Within every second of a film, the motion of the projector is interrupted twenty-four times. All pictures appear on the screen for only a fraction of a second. The swift projections of images are too fast for the human eye, which does not pick up individual pictures, but rather sees a connected motion. As early as the late nineteenth century, this physiological wonder was exploited to carry out the first successful cinematic exercises.

Films have maintained a prolific output of scripts with their take on mental illnesses, such as the rare syndrome of Dissociative Identity Disorder (DID) (Byrne, 2001). Films based on Dissociative Identity Disorder are a popular genre, whose influence can be seen throughout mainstream cinemas. Exploration of this illness in cinemas is an important idea because in that it touches on issues in film studies, psychiatry and the mythology around mental illness. The public has a perception of mental illness as violence and the belief that every mentally-ill person harbours great dark secrets within them is the first aspect that creates suspense in the people to watch and scriptwriters to plot such narratives (Malla et al., 2015).

This genre moreover acts as a detective story. The transition from a regular guy to a mass murderer questions the identity crisis in a person and their personality. The evolution of a character with fading identity and dual personality provides the dramatic presentations which give way to flashbacks and a variety of dissociative states of this syndrome (Brenner, 1994). The area of research will be looking at how internal human drama, the problem of fading identity and double personality is being portrayed in the film genre because of this illness.

In addition to providing great scenes, Dissociative Identity Disorder films provide great characters (Byrne, 2001). Actors must jump at the chance to evoke such drama, with the opportunity to immerse them in multiple methods and moods of acting. Furthermore, this paper examines gender in a certain parameter to draw out a comparison of women in this genre.

This research paper focuses on two primary films- Spellbound (1945) by Alfred Hitchcock and Identity (2003) by James Mangold. Both of these films are psychological thrillers since the central characters suffer from psychological illness- Dissociative Identity Disorder. A study on both the films on how this illness triggers an element of suspense in the minds of the audience and the changing phases in the portrayal of memory, suspense and identity in psychological thriller movies through the narrative of these primary texts. Something more attractive to the audience is the dramatic moment in such a film, where all is revealed about the twist and when resolution occurs. 


\section{Literature Review}

Literary techniques are an important factor in films. The first major book on film studies, Hugo Munsterberg's The Photoplay (1916), inaugurates psychological film theory by analyzing mental reactions and processes that take place when one watches a movie (Langdale, 2002). Munsterberg and early film theorists regarded the spatial and temporal freedom of film storytelling to be very similar to the processes of the human imagination (Münsterberg, 1916). A crucial observation for future film studies was their belief that inner human reality can best be expressed through the medium of film. Even though essentially rooted in a formalist- structuralist methodology, the concept of a montage of the Russian director Sergei Eisenstein is connected to Munsterberg's psychological reception theory. Eisenstein does not focus primarily on the portrayal of accurate reality in film, but instead, he argues that contrapuntal cuts can create specific scenes in a viewer's mind. According to this concept of montage, one should not aim for seamless cuts but contrast and confrontation instead. Based on these ideas, proponents of Russian formalist film studies expressed a strong aversion toward 'talkies'. They argued that a realistic soundtrack, including dialogue, noises, and music, does not fit the montage concept of dialectic antithesis. In a similar vein, the German Gestalt psychologist Rudolf Arnheim in the 1930's also argued that sound corrupts the artistic qualities of a film. In sum, this period is indebted to a formalism approach to film, as it does not emphasize realistic representations, but the film's potential for abstractions and illusions.

In contrast to the Russian formalism, the realism movement after World War II regarded mise-en-scene and screen layout as the basis of illusionary, film reality (Klarer, 2014). Examples are found especially in silent movies, as well as in the techniques of famous directors like Orson Welles. The French 'auteur theory', created and advocated by Andrew Sarris and Francois Truffaut, analyses specific characteristics of great filmmakers. Like author-oriented approaches, it views a director's oeuvre as an expression of his or her style. This could be problematic when discussing a film. While authors are usually solely responsible for their works, a director is only one of many people who contribute to the creation of a movie (Harris, 2013). Because of these limitations, auteur theory soon lost its momentum, giving way to more film- specific approaches. Similar to text-oriented studies in literature, they are among the most productive fields of research of the second half of the twentieth century. Christian Metz's Film language (1963), for example, is the major proponent of film semiotics, which tries to explain film as a language- like, semiotic system, restricted by several media-specific codes that create film narration.

Semiotics, deconstruction, and Marxist theory as well as the psychoanalytical works of Jacques Lacan, have been shaping literary studies as well as film studies since the 1970s. Special importance must also be attributed to feminist film studies. In 1970, the essay of Laura Mulvey Visual Pleasure and Narrative Cinema triggered an extensive discussion about the 'male gaze' in film. According to Malvey, traditional Hollywood cinema is based on the psychoanalytical processes of a male viewer, consequently fragmenting and objectifying the female body into eroticized objects of the male gaze. In recent years, this 
approach has been further explored through questions of film gender construction, based on Judith Butler's publications on Gender Theory. The latest developments in film and media theory focus on narrative aspects of recent digital phenomena such as computer games or augmented reality simulation.

In the nineteenth century, before the main formalist-structuralist theories concerning the twentieth century, biographical criticisms emerged and have grown into a dominant movement. Author-centered approaches focus aspects that could have inscribed the text on a subconscious or involuntary level. The reality that Shelley had a miscarriage during the outlay in which she wrote her novel Frankenstein (1818) is frequently compared to her texts. This has paved the way to Psychoanalytic Literary Criticism, which comprises of a movement that seldom deals with the author but attempts to highlight a general psychological viewpoint in a text that does not connect to the author. Under the impact of Freud, Psychoanalytic Literary Criticism developed the study of psychological features ahead of the author to hide a scope of intrinsic textual aspects. For situations, characters in a text can be analyzed psychologically, as if they were actual people. An example that has been usually cited during this connection is the psychological state of Hamlet in Shakespeare's drama; psychoanalytic critics examine whether Hamlet is mad and, if so, from which psychological illness he is suffering. Sigmund Freud too adopted from literary texts in his analysis of certain psychological aspects. In the latter half of the twentieth century, Psychoanalytic Literary Criticism reacquired momentum under the influence of the French analyst Jacques Lacan, notably within the Anglo-American world. The concern in psychological phenomena indirectly helped the spread of the so-called reader-centered approaches. They concentrate on the response of a text by a reader or the interpretation, which can be seen as an investigation of psychological happenings within the widest understanding of the term.

Due to the different forms and media, films are often classified under the heading performing arts and likewise not drawn into the limelight of research as people believe films can't be as close to the value of a book or any texts. Major expansions of literary theory have consequently been adopted or adapted by film studies because they use actors as their primary means of expression. Although films have their specific characteristics and terminology, it is plausible to analyze film by tracing methods of literary criticism, as film criticism is nearly compared to the traditional methods concerning textual studies. For example, approaches such as psychoanalytical theory or feminist film theory view film within a more comprehensive contextual framework. The visualization concerning the action in films is not left solely to the thought of a reader, but rather stretches to life in each performance. Because of the factor of this genre, a performance stands at the center of attention.

The carriage of two or more split identities or personality states that continually have power over a person's behavior is identified as Dissociative Identity Disorder (DID) alternatively Multiple Personality Disorder (MPD), which is a psychological disorder. A personality with 
Dissociative Identity Disorder cannot recollect his/hers key personal information, which can be explained as forgetfulness and also own highly distinct memory variations, which can fluctuate (Bhandari, par. 1). Some psychologists believe the cause to be childhood trauma. Such individuals face a serious issue with their identity, memory, and personality. Narratives depicting this disorder are written in a wide range. Narratives are always from different perspectives. These texts have not only helped researchers and practitioners to go beyond the disease and understand the experience, perspective, and dilemmas of illness of the patient but take the readers or audience to another world of internal human drama. These people are portrayed in texts, as dangerous to society by giving them the face of evil. It rather gives us a warning rather than creating awareness.

\section{Methodology and Procedures}

Psychological thriller films that use psychological illness are often seen narrated by the people who are with them. The narration in the films Spellbound (1945) and Identity (2003) are also constructed in the same way. In both films, the trauma of the person who has Dissociative Identity Disorder is explored. This study focuses on the depiction of the elements; memory and identity in psychological thriller films. It explores the internal human drama, the problem of fading identity, and double personality through the characterization in these movies. A comparative study between the characters from both the films is done to show the varied perspectives and experiences of these patients which have both similarities and differences.

\section{Results and Discussion}

The film, Spellbound (1945) is directed by Alfred Hitchcock, and it is classified as a psychological mystery thriller film. The story revolves around the life of a women protagonist, Dr. Constance Petersen, who is working as a psychoanalyst at Green Manors, which is a therapeutic community mental hospital in Vermont. Just like many other psychological thrillers, this film also uses the power of the human mind to retrieve clues to investigate a crime. In this film, it is not just the patient, John Ballantine, who goes through the issue of fading identity, but even Dr. Constance Petersen.

A memory of an Amnesia patient is always scattered and it sounds puzzling to a normal human being. This illness is a factor for creating suspense in the minds of the audience along with a criminal investigation and camera movement. According to the book by National Collaborating Centre for Mental Health, for survivors of traumatic events, elements of their initial experience are later re-experienced through post-traumatic intrusions such as memories, flashbacks, and reactivity to cues reminiscent of the original event (par. 2). This is a reason why the film narrative uses dream sequences, flashbacks in its script. At times what a person sees in his dreams can be the thoughts of his sub-conscious mind. The disease Amnesia is associated usually with a "host" personality, which is within the person. This host is the one who recognizes the person's real name. Ironically, the host's personality is usually forgetful of the residence of other personalities inside them. Such individuals face a 
serious issue with their identity, memory, and personality. This can be applicable in Ballantine's situation where Petersen had to draw out the activated Guilt Complex of Ballantine. The Guilt Complex was activated when the human mind disturbed badly. For example, Ballantine had to face this internal human drama in his childhood and when he saw the murder of Dr. Anthony and could not surrender as a witness. He instead transformed into the Doctor who died because of his illness ("Dr.Petersen" 01:52:30-52). Often when Petersen asks Ballantine to remember things he faints because of extreme conflict of internal human drama to recognize his true self.

Along with the investigation of the crime, Ballantine and Petersen discover their true identity and personalities by opening the hidden doors of their minds. Initially, we see Petersen as a woman who is only dedicated to her profession and does not value her inner instincts ("Dr.Petersen" 00:07:20-11:06). It's only through Ballentine that she discovers the other end of her human mind and desires. Mary Carmichael is the alter ego of Dr.Petersen. She represents the dual personality of the internal mind, where she could react to the men centric world, rather obeying their orders and keeping quiet. Thoughts, feelings, and experiences usually imperceptible to an observer can be depicted on the movie screen through a variety of cinematic devices such as voice-overs, jump cuts, flashbacks, close-ups, alterations of sound, color, and image, and panning techniques (Butler \& Palesh, 2004).). Both Ballentine and Petersen needed each other for discovering their identities. Depiction of parallel lines, trains, and emotions show the connectivity of each other and their need in life. This is the reason why only Petersen could prove that Ballantine was innocent.

In the film, Identity (Mangold, 2003), the plot's twist is something that amazed the audience. The story revolves around ten strangers who were caught in stormy weather. They get stuck coincidentally for a night at a remote and rundown motel in an isolated area. Midway through, we see in the film that the strangers are seen brutally murdered one by one, and the rest of them get concerned to begin examining clues to the identity of the murderer among them. The film uses reverse chronology structure to show several events that take place in the hours before the characters arrive at the motel. At the hearing, the contents from Malcolm's diaries are shared where there was distinct handwriting which indicated Malcolm suffers from an intense case of Dissociative Identity Disorder and holds eleven different personalities. Fingerprints and handwriting are unique to an individual. It defines one's personality and identity.

This movie makes use of varied film techniques such as camera, sound, movements, narration, lighting, characterization, etc. to show the elements of memory, identity, and suspense. James Mangold describes Identity (2003): As a puzzle, not only in the viewers' experience but in my own. Identity and identification is a process. The movie plays with both time and memory. The movie is a collection of sinners. The scenes of the film is a series of cuts almost like I thought of them, and it very much plays to the end of the film almost like thoughts in a mind, the way we'll connect an object or memory and then kind of zap around, if you will, in the kind of the fast forward of our brains (Fuchs 1). 
In a film, it's said that the camera and its movements are like human eyes. This is a feature that gives color and context to the script. In this text, as Mangold says it works like thoughts of mind through flashbacks and nightmares to portray memories. The movie tries to show the point of view of all the characters. For example; in the second scene we observe a family on holiday driving on a stormy night. As the tire blows out, George gets down to fix it and Alice holds the umbrella over him. Then she peeks inside the car to wave at Timothy, and next, we see her being hit by a car. The next angle is being looked at from her son's viewpoint, inside the family's car. Shortly, the scene again slips to the point of view of the driver who hits her, the depressed ex-cop and current limo driver Ed (00:04:59-09:01).

The usage of the camera as an eye opens doors to memories of a character which parallelly raises the element of suspense in the minds of the audience. It can also be noticed that all flashbacks are pictured in a dark setting with stormy weather, isolated area, and troubled characters; which in turn tries to show the conflict in the memory of the individual's thoughts. Since the patient suffers from Dissociative Identity Disorder, his memories are fractured. When the mind is exposed to extensive trauma it may fracture ("Dr.Malick" 01:11:35-44). The host body only remembers what he had learned in his childhood such as the poem.

Just like the title suggests, identity can be understood as what it means to be a person. It can be defined by what you are and what you are not. This movie tries to investigate the fading identity of the protagonist-Malcolm Rivers. The eleven personalities can be looked at as alter sides of him. For example; Timothy, as his childhood alter ego, where he wanted to react to situations in which his mother, who was whore put him through a tough life. Ed can be analyzed as the character where he wanted to be in his life but couldn't. This can be understood because even Ed had gone through a psychological trauma like Malcolm.

Existentialism and modernism are other factors that bother the fading identity of the protagonist. The protagonist is caught between the ideas of modernism in life which he wanted to escape like Paris. This can be understood through the naming of the eleven personalities which connect along with different cities; such as Larry Washington, Paris Nevada, Alice York, etc. Paris is portrayed as an altered side of Malcolm, where he wanted to spend his life in the countryside and doing some sort of agriculture. The eleven personalities can be seen as the internal drama of identity conflict. These characters portray wanted Malcolm wanted to be in life and who he couldn't be in his life. Instead of being in dual personality, the protagonist takes up multi-personality to show his internal drama, which makes the text unique.

The camera movement and gothic settings are not only the factors that lead to the element of suspense in the audience but also the narrative and the performance of the characters. Other than flashbacks, the text also uses epigraph of a famous poem of William HughesAntigonish. This poem which was written in 1899 is known to have gothic ideas, which creates a kind of suspense in the audience. The protagonist recites this poem in various situations, hoping to be in his original identity than being controlled by society and its 
norms. "Go away, go away, don't you come back any more! / Go away, go away, and please don't slam the door" (Hughes, p. 9-10).

Dissociation has virtually boundless potential for delivering curves into storylines. Other than mystery and suspense of the narrative, it can also be easily related as a metaphor for common anxieties in humans concerning memory, identity, and conflict in human nature. Dissociative Identity Disorder, Amnesia, and the sort of memory have been topics of concern among the audience or readers. Depictions of dissociation in films are not an ordinary experience because they share fundamental existentialism of alternate realities of people. This the reason why there is a huge appreciation of the audience of big screens.

Over time we realize that gender roles and gender stereotypes have affected the characterization in movies and other texts. The concept of a stereotype was introduced in 1922 when Walter Lippman used it to describe the "typical picture" that comes to mind when thinking about a particular social group (Macrae et al., 1996, p. 75). A stereotype can be examined as a cognitive method or procedure, employed by our mind to analyze the complex barrage of information it undergoes. From this attitude, a stereotype may be a process of understanding, which accomplishes through tagging individual people into a gaggle kind. This interpretation of a stereotype, however, ignores the crucial issue of content. As a "typical picture" of a social group, a stereotype may be accurate or inaccurate when viewing it from a panorama of justification and righteousness. It is, though, the negative, the wrong, and therefore the unjustified stereotypes that provoke us most concern. Adequate knowledge of a stereotype must also combine the idea that stereotypes are not only carried within an individual's mind but also survive at a collective level.

This shared detail of the content of stereotypes makes it possible to locate some regularly recognized gender stereotypes. For example; that females are emotional and unpredictable, they are faulty drivers and like desserts, or that men are rational and effective, inadequate at housework, and like sport. With these features in mind, a gender stereotype can be defined as a standardized and often pejorative thought or image tied about an individual based on their gender. At a generic level, the impacts of stereotyping can mean that, rather than treating people as individuals, 'we treat them alternatively as artificial selves, which means as an enlargement of the class we have constructed.'

Women are a focal point in the films selected in this research study. In Hitchcock's movie, the portrayal of gender roles fascinates the audience, making a better understanding of how men and women should be viewed in his films. Dialogues also play an important factor in his movies because to an extent it states Hitchcock's feelings or politics about men and women. Spellbound (1945) is a prime example to understand the above statement.

In the selected films, men are displayed as flawed and needing help, while women are presented as care-givers. Men presume women have an interest in money or status or success. Men are always seen as reluctant to take action until the desire of a woman, to solve the mystery. Dr. Constance Petersen is the central woman protagonist in this film. In scene 
one, it's noticed that one of the other doctors is attracted to her and kisses her, but she brushes him off, assumingly because she is dedicated to her career ("Dr.Petersen" 00:10:28-40). Women, being the thing of desire, hold the facility, and use it to control men. It is not enough that women are shown this way, but also they frown upon when they don't respond to male attraction and try to be independent. Again when Constance refuses help from men in the movie it is negatively connoted ("Dr.Petersen" 00:23:16-39). Hitchcock seems to be subverting the message that women are only complete when they are with a man through this scene. Men are shown as superior and chase the ladies. Older men, especially, frown upon the younger men and tease the ladies within the film. In the film, it is the man that is forward, suave, and handsome. For example, he has to approach her and tell her why she came to his room. And compliment on her looks, which initiates to their kiss.

Hitchcock shows his true feelings about women when Constance falls in love with the film. Suddenly she displays restlessness and can't help but go to Ballantine's room, suggesting that women are at the mercy of their sentiments, and that logic does not restrain their actions. At one point in the film, Dr. Alex comments that "the mind of a lady crazy is working on a rock, the bottom level of intellect ("Dr. Alex"01:19:35-38)." Men meanwhile are shown to be calm, logical, and questioning. After John Ballantine and Constance are on the run from the police, Hitchcock shows the difference between men and women in his opinion. Constance is willing to suspend belief and have faith within the man she loves while John isn't convinced and questions his innocence. Men tell her she's even crazier than her patients once she falls in love.

Hitchcock's movies have a recurring role as the suspicious investigator. All of the investigators are male power figures, detectives, or cops. Spellbound (1945) has a heavy dose; from cops who question her to see what she knows about John Ballantine, to the hotel investigator, to the railroad cop, to the detectives in Dr. Alex's office. Hitchcock strengthens his depiction of men as questioners who reach decisions following careful thoughts and using logic to every situation by combining these characters in his films. These men are constantly seen to be fooled by women in the films, emphasizing their devious and deceitful nature.

While most of the representations of girls are negative in Hitchcock's films, there's also the positive aspect of loyalty that's shown in Spellbound (1945). Constance believes in her man and defends and fights against even when it seems all hope is lost to prove his innocence. For example, in her final confrontation with Dr. Murchison, she puts herself in danger to get a confession from him ("Dr.Petersen and Dr.Murchison"01:47:54-54:44). It is only because of her verbal interrogation with Dr. Murchison she could escape with her life, without being shot. As the title says 'Spellbound', the quality of the character Petersen, is devoted to spellbind the audience. Not just physically, but with her intelligence too. Dr. Murchison, instead, turns the gun on himself. In this scene, Hitchcock once again reaffirms the portrayal of women as the instigators of action. They may not take action themselves, but they can provoke men into action. 
Moving to the text, Identity (2003) by James Mangold is like many other Hollywood narratives that focus on the fictional story of the male lead. He has to defeat some obstacles to conclude in society. Gender stereotyping in the texts is also seen as femininity associated with domestic duties and sexuality. Krin Gabbard explains films play part in changing cultural norms, too: acting career exemplifies a trajectory in the representation of masculinity from the traditional notion which is described by adjectives like strong, active, determined, leader, fighter, muscular (60). Mangold has shown in this movie men as being the central characters. It is only men who are indulged in an investigation and solving problems. Women are asked or forced to follow what they are asked.

In a study, Tuchman examined media depictions of American women from the 1950s onwards. Her findings were that women were stereotyped either as sexual objects, or as housewives, or in jobs that were reflections of their domestic/caring role (Pilcher and Whelehan, 2016, p.167). Even in Identity (2003), we see that Paris and Caroline turn to attract the male gaze while Ginny, Alice, and Malcom River's mother are seen as caregivers. Though Paris was a prostitute, Ed sends her along with Timmothy to take care of him at the end ("Ed" 01:04:06-23). The independent women in the picture, i.e. Paris and Caroline, are not headed by a man but the rest are. It's believed that the identity of a woman comes from a male. They (Paris and Caroline) are seen working for themselves and looked from a negative characterization of being a whore, a female with a bad character or good for nothing. Films have slipped to reflect the spectrum of women's lives in reality. One finding signified that women remain to be underrepresented on television. According to the 1999 European Commission, in Britain, only 30 percent of people on television are women. Moreover, studies also showed that, compared with men, women portrayed in the media are younger, more likely to be shown as married, and less likely to be shown in paid employment (Wood, 1994). Even in the movie, Caroline being an actor faced trouble with her carrier and there's no one to help her. This can be understood from a scene where she talks in front of a mirror, drinking and preparing herself to talk to the officials about her harsh working environment ("Caroline" 00:25:28-37).

Both the narrative and filming have captured the minds of the audience in this thriller. From the initial half of the 1970s, the purpose of the audience or reader heightened the focus of psychoanalytic attention. The issue of how the audience sees and comprehends films became necessary. Criticisms of the film viewers' identification led to concerns of the role of the camera in establishing up the narrative frame of the film through the interplay of the points of view connected in watching a film. The profoundly influential essay, Visual Pleasure and Narrative Cinema (1989) by Laura Mulvey gave another stimulus for addressing the issue of reception and triggered the association of feminism in psychoanalytical debates concerning films.

A high-minded fact to look on is that it's not always a woman who has problems like in the traditional movies "madwoman" or "yakshi". In this text, the person with the disorder is a male and has murdered a mass. However, one must read through the grains, with the idea that it was Malcom's mother who has triggered the factor of the disorder. A lady is seen as 
the center of creating problems, for example, the harsh driving of Paris and Malcom's mother being a whore has created trauma for her child and her parenting is not good in the society. Towards the end, it's only the men who remain. In texts, we come across that woman being portrayed as bad drivers, having a bad temper, tricky, and can't take care of themselves. Therefore, they need a male to protect them like police officers to care for the ladies, in the movie. They are always male-accompanied.

Examination of this illness in cinemas is a significant idea because within that it touches on subjects in film studies, psychiatry, and mythology about mental illness. The common understanding concerning mental illness as violence and the dogma that all mentally illperson harbors great dark mysteries within them is the initial slant that creates suspense in the people to view and scriptwriters to plot so narratives. Furthermore, this genre acts as a detective story. It's observed that, the shift from a normal person to amass killer in the film questions the identity crisis in a person and their personality. The evolution of a character with fading identity and dual personality provides the dramatic presentations which give access to flashbacks and diversity of dissociative states of the syndrome. The dissertation had looked at how internal human drama, the problem of fading identity, and double personality is portrayed in the film genre because of this illness. A study on both the films on how this illness triggers an element of suspense in the minds of the audience and the changing phases in the portrayal of memory, suspense, and identity in psychological thriller movies through the narrative of these primary texts. Something more engaging to the audience is the dramatic note in such a film, where all is unveiled about the twist and resolution occurs. In an interest in providing exceptional scenes, Dissociative Identity Disorder films contribute great characters. Actors must spring at the chance to evoke such drama, including the chance to absorb them in varied styles and conditions of acting. The paper additionally viewed gender in a certain parameter to draw out a comparison of women in this genre. The results show that apart from building suspense and mysteries with the identity issue, these thrillers are also seen challenging the stereotypes and inequality in society through the female characters for the consumerist audience. Hence it attempts to break the chains of legitimated stereotypes in the society which creates binaries in the life of people.

\section{Conclusion and Suggestion}

The objective of this research paper was to study the portrayal of memory, gender, and identity in psychological thrillers, on two primary films- Spellbound (1945) by Alfred Hitchcock and Identity (2003) by James Mangold. Both these films are psychological thrillers with the main characters suffering from psychological illness-Dissociative Identity Disorder. The portrayal of illness in psychological thrillers has attracted a lot more audience to seats. Dissociative elements such as memory and identity of the mind perhaps have permeated the film-going experience. The picturization of the fading identity and the double personality of the characters are central to the interior experience. The capturing of Amnesia and its related themes of memory, identity, and distributed consciousness are common 
materials in recent films because they can stretch to basic humanistic concerns and contemporary psycho-social issues. This genre creates suspense by not only working as a detective thriller to solve the mystery of illness but also helps the audience to find their identity. Flashbacks are the actual characteristics that structure our internal human drama through dreams.

In Spellbound (1945) and Identity (2003), women like Dr. Constance Petersen and Paris, break gender stereotypes. Their individuality and dreams of a better future prioritize the narration of the script. To an extent, they try to resist and give importance to their inner mind and not society. Both of the film texts have a difference in fifty or more years. Apart from creating suspense and mystery with the identity issue, they are also seen questioning the stereotypes and inequality in society through the female characters for the consumerist audience. Psychological thrillers can also be considered as a fantasy. The elements of suspense take one to the other side of life. In this manner, it attempts to break the chains of legitimated stereotypes in the society which creates binaries in the life of people. One also understands that attracting consumers is not just to create profit for the industry, but to create an awareness of one's personality, identity, and equality in gender.

\section{Conflict of Interest}

The author of the article declares no conflict of interest.

\section{Funding}

This research study was not funded by any institution. The author conducted the study on her own expenses.

\section{References}

Abrams, M., \& Harpham, G. (2014). A glossary of literary terms. Cengage Learning.

Brockmeier, J., \& Carbaugh, D. (Eds.). (2001). Narrative and identity: Studies in autobiography, self and culture (Vol. 1). John Benjamins Publishing.

Brenner, I. (1994). The dissociative character: a reconsideration of "multiple personality". Journal of the American Psychoanalytic Association, 42(3), 819-846.

Byrne, P. (2001). The butler (s) DID it-dissociative identity disorder in cinema. Medical Humanities, 27(1), 26-29.

Butler, L. D., \& Palesh, O. (2004). Spellbound: Dissociation in the movies. Journal of Trauma \& Dissociation, 5(2), 61-87. https:// doi.org/ 10. 1300/ j229 v05 n02_04

Kivikuru, U. (1999). Images of women in the media: Report on existing research in the European Union. Employment and social affairs, equality between women and men. Luxembourg: European Commission Directorate-General for Employment, Industrial Relations, and Social Affairs Unit V/Ds Officer for Official Publications of the European Communities. 
Klarer, M. (2014). A short literary history of the United States. Routledge.

Fuchs, C. (2003). Identity. PopMatters. https://www.popmatters.com/identity- dvd2496248153.html

Gabbard, K. (1996). Jammin' at the margins: Jazz and the American cinema. University of Chicago Press.

Glenn, C. (2014). Jean-Luc Godard and Francois Truffaut: The Influence of Hollywood, Modernization and Radical Politics on their Films and Friendship.

Grainge, P. (2003). Memory and popular film. Manchester University Press.

Harris, E. (2013). The right to final cut approval: The struggle for creative control between the director and the studio in feature filmmaking. Chicago-Kent College of Law at Illinois Institute of Technology. Retrieved from www. kentlaw. edu/perritt/courses/seminar/E Harris Final Seminar Paper. pdf.

Hitchcock, A. (Director). (1945). Spellbound.

Klarer, M. (2005). An introduction to literary studies. Routledge.

Langdale, A. (2002). Hugo Münsterberg on film: The photoplay--a psychological study and other writings. Psychology Press.

Lewis, D. O., \& Putnam, F. W. (1996). Dissociative identity disorder/multiple personality disorder. WB Saunders.

Macrae, C. N., Stangor, C., \& Hewstone, M. (1996). Stereotypes and stereotyping. Guilford Press.

Mangold, J. (Director). (2003). Identity.

Malla, A., Joober, R., \& Garcia, A. (2015). "Mental illness is like any other medical illness": a critical examination of the statement and its impact on patient care and society. Journal of psychiatry \& neuroscience: JPN, 40(3), 147.

Minsky, R. (2014). Psychoanalysis and gender: An introductory reader. Routledge.

Mulvey, L. (1989). Visual pleasure and narrative cinema. In Visual and other pleasures. pp. 14-26, Palgrave Macmillan, London.

Münsterberg, H. (1916). The photoplay: A psychological study. D. Appleton.

Packer, S. (2007). Movies and the modern Psyche. Greenwood Publishing Group.

Pilcher, J., \& Whelehan, I. (2016). Key concepts in gender studies. SAGE. to understand psychopathology. Hogrefe Publishing.

Tan, E. S. (2018). A psychology of the film. Palgrave Communications, 4(1), 1-20.

Wedding, D., \& Niemiec, R. M. (2014). Movies and mental illness: Using films to understand psychopathology. Hogrefe Publishing.

Wood, J. T. (1994). Gendered media: The influence of media on views of gender. Gendered lives: Communication, gender, and culture, 9, 231-244. 